\title{
MORFOMETRIA COMO SUBSÍDIO À ANÁLISE DOS PROCESSOS EROSIVOS NA MICROBACIA DO CÓRREGO GRANDE- EUNÁPOLIS - BA
}

\author{
Claudia Mendes Cordeiro ${ }^{1}$ \\ Danusa Oliveira Campos² \\ André Luiz Dantas Estevam ${ }^{3}$ \\ Diego Corrêa Maia ${ }^{4}$
}

Resumo: Este artigo tem como objetivo aplicar a morfometria como subsídio à análise de impactos dos processos erosivos na Microbacia Hidrográfica do Rio Córrego Grande localizada na Região Extremo Sul do Estado da Bahia. A área investigada drena a zona urbana e periurbana do município de Eunápolis. 0 crescimento da urbanização e da agropecuária sobre os relevos que compõem a microbacia hidrográfica produzem impactos ambientais, principalmente no solo e na água. É comum a ocorrência de movimentos de massa, rastejos, ravinas e voçorocas ao longo das vertentes que trazem insegurança às comunidades residentes em áreas de risco. Para esta investigação foram analisados parâmetros morfométricos areais e lineares, índices do terreno e mapeamentos temáticos da bacia no intuito de estabelecer correlações entre os fatores hidrográficos e os impactos antropogênicos ao longo dos canais fluviais. Neste contexto, é de extrema relevância estudos mais aprofundados para subsidiar as políticas públicas destinadas ao planejamento de uso solo e melhoria da qualidade de vida das comunidades que residem na microbacia hidrográfica.

Palavras Chave: Morfometria, Microbacia Hidrográfica, Processos erosivos, Urbanização, Impactos Ambientais.

\section{MORPHOMETRY AS A SUBSIDY FOR THE ANALYSIS OF EROSIVE PROCESSES IN THE MICROBASIN OF CÓRREGO GRANDE - EUNÁPOLIS - BA}

\footnotetext{
Abstract: This article aims to apply morphometry as a subsidy to the analysis of the impacts of erosion processes in the Córrego Grande River Watershed located in the Extreme South of the State of Bahia. The investigated area drains the urban and peri-urban area of the municipality of Eunápolis. The growth of urbanization and agriculture on the reliefs that make up the hydrographic microbasin produce environmental impacts, mainly on soil and water. It is common for mass movements,

${ }^{1}$ Professora do Instituto Federal da Bahia - Campus Eunápolis. Email: claudia.cordeiro@ifba.edu.br

${ }^{2}$ Professora Adjunta da Universidade Federal do Sul da Bahia (UFSB). Email: danusa.campos@ufsb.edu.br

${ }^{3}$ Professor Titular B do Departamento de Ciências Humanas da Universidade do Estado da Bahia - UNEB (Campus V -

Santo Antônio de Jesus).Email: alestevam@uneb.br

${ }^{4}$ Professor Adjunto da Unesp - Campus Rio Claro (SP). Email: d.maia@ unesp.br
} 
crawls, ravines and gullies to occur along the slopes that bring insecurity to communities living in risk areas. For this investigation, areal and linear morphometric parameters, terrain indices and thematic mapping of the basin were analyzed in order to establish correlations between hydrographic factors and anthropogenic impacts along the river channels. In this context, more in-depth studies are extremely relevant to support public policies aimed at planning land use and improving the quality of life of communities residing in the hydrographic microbasin.

Keywords: Morphometry, Hydrographic Microbasin, Urbanization, Erosive processes, Environmental impacts.

\section{INTRODUÇÃO}

As cidades são na atualidade espaço do contraditório por representarem ao mesmo tempo, áreas de desenvolvimento econômico (indústrias/comércio, lazer e cultura) e de desigualdades sociais e conflitos socioespaciais. Em que pese toda a discussão de sustentabilidade das cidades na contemporaneidade, é lícito falar que esse processo ainda não supre as grandes demandas urbanas, como por exemplo, os impactos ambientais que acometem os sítios urbanos nas metrópoles e cidades médias (ARAÚJO, 2006; MARGUTI et al. 2018;).

Projetos técnicos, estudos preventivos e de mitigação para controle dos impactos ambientais, concentram-se nas áreas dos grandes eixos metropolitanos, relegando às cidades de pequeno e médio porte projetos difusos que não atendem a urgência de prevenção de impactos ambientais (BRASIL, 2021b; BRASIL, 2021c). Tais projetos e planos nem sempre condizem com a realidade de um planejamento socioambiental coerente com as necessidades reais dos citadinos. Em muitos casos, relatórios técnicos e PDDU's (Planos Diretores de Desenvolvimento Urbano) não são devidamente atualizados e até mesmo não obedecem aos critérios das audiências públicas e/ou consulta popular (OLIVEIRA, 2018; MERGEN, ZANETTI, RESCHILIAN, 2018).

Os diversos impactos e riscos ambientais decorrentes dos usos indevidos dos solos em áreas urbanas são amplamente identificados e os riscos diagnosticados estão associados quase sempre aos episódios geomorfológicos catastróficos (DE ALMEIDA OLIVEIRA; ROBAINA, 2015). Tais eventos ocorrem em grande parte devido à inexistência do saneamento básico e de gestão adequada dos resíduos sólidos e de políticas habitacionais condizentes com a condição do terreno.

Os usos indisciplinados dos solos e impactos decorrentes ao longo das Áreas de Proteção Permanentes (APPs) desencadeiam transbordamentos dos rios, deslizamentos, desbarrancamentos, fluxo de lama, enxurradas, bem como a criação e proliferação de focos de doenças ligadas à contaminação água com reflexos no aumento do índice de verminoses, doenças de pele, problemas respiratórios, dentre outros.

No que se refere ao planejamento ambiental das cidades, a aplicação de estudos morfométricos aplicados às bacias urbanas mostram-se muito úteis para dirimir a questão dos impactos em prol de um melhor ordenamento territorial dessas áreas. Moreira e Rodrigues (2010) complementam discorrendo que a compreensão dos parâmetros morfométricos auxilia no diagnóstico de susceptibilidade à degradação ambiental, conferindo o devido suporte ao planejamento e manejo das microbacias. 
Os impactos ambientais relacionados os uso do solo urbano estão presentes em cidades de pequeno/médio porte ainda que não sejam amplamente publicizados devido à posição periférica dessas cidades no contexto da rede urbana e/ou devido a condições que de uma frequência maior para a ocorrência de um dano fruto de um impacto no terreno, por exemplo. Essas cidades de pequeno e médio porte seguem um padrão crescente de novas construções sem um planejamento de uso do terreno e manejo dos recursos hídricos que possibilite avançar em projetos urbanos condizentes com as normas ambientais (DE ALMEIDA OLIVEIRA; ROBAINA, 2015).

Estudos que mensuram a dinâmica geohidroambiental em áreas urbanas podem mitigar e prever riscos, assim como nortear os planos de gestão urbana (COELHO NETO; 2005, 2007), principalmente em áreas densamente povoadas com altas taxas de crescimento e atração populacional.

No contexto de planejamento urbano, muito se tem discutido sobre priorização de bacias hidrográficas no planejamento do solo e da água e nesse trabalho inserimos essa discussão a partir das assertivas/problematizações sobre priorização de uso de bacias urbanas apresentadas por Banerjee et al. (2015) e do papel da morfometria para a conservação do solo e água e para mensuração de impactos plurierosivos (SUKRISTIYANTI e LESTIANA, 2018, MURALITHARAN e PALANIVEL, 2019., DASH et al. 2019).

Os resultados advindos da análise morfométrica associadas a técnicas de geoprocessamento e sensoriamento remoto têm se mostrado muito viáveis para a caracterização não só de bacias hidrográficas, mas também para o planejamento ambiental de suas paisagens. Estas técnicas foram utilizadas por Muralitharan e Palanivel (2019) que categorizaram classes de escoamento de várias sub-bacias hidrográficas em Karur, Tamil Nadu - Índia por meio de dados de sensoriamento remoto, GIS e parâmetros morfométricos lineares e areais. A junção destas técnicas possibilitou concluir que a integração dos parâmetros morfométricos demonstrou ser uma metodologia viável para a avaliação rápida de bacias hidrográficas propensas ao escoamento, portanto elemento importante para gestão urbana de áreas de risco.

Dash et al. (2019) aplicaram análise morfométrica usando técnica geoespacial para conservação do solo e da água. Os resultados permitiram categorizar o potencial de escoamento, o pico de vazão e as condições de permeabilidade de solo e infiltração e possibilitou inferir sobre o potencial do uso das técnicas de geoprocessamento na modelagem hidrográfica. Evidenciaram também que a extração do recurso, sem essa análise, pode incorrer em erros no sistema de coleta de água subterrânea com consequente problema erosivo e outros impactos socioambientais.

Banerjee et al. (2015) utilizaram abordagem integrada em GIS para avaliação morfométrica na bacia hidrográfica de Swarnrekha, Madhya Pradesh, Índia e comprovaram a eficácia dos dois métodos para a caracterização da bacia e destacaram a intrínseca relação entre dinâmica hidrográfica e relevo. Segundo os autores, a análise quantitativa das bacias por meio da avaliação morfométrica é vital para compreender a configuração hidrológica de qualquer terreno, fator primordial para a gestão dos recursos hídricos e planejamento de bacias urbanas, mesmo em nível micro como a microbacia de Swarnrekha.

Sukristiyanti e Lestiana (2018) concluíram que a avaliação morfométrica é o melhor método para identificar a relação de vários aspectos areais da bacia para o planejamento de bacias hidrográficas, no entanto, pontuam o cuidado com a qualidade dos dados de entrada e a importância do enquadramento e inter-relação 
dos parâmetros, para assim poder gerar uma análise consistente e boa comparação inter-bacias. Beltrame (1994) corrobora a informação dizendo da importância da inter-relação da avaliação morfométrica com os aspectos da geologia, litologia, solos, relevo clima e experimentos de campo.

Nessa perspectiva, diversos autores (DA CUNHA, 2016; SUKRISTIYANTI e LESTIANA; 2018, MURALITHARAN e PALANIVEL, 2019, DASH et al. 2019, DAS, 2021) tem ampliado o uso das técnicas morfométricas, Sistema de Informação Geográfica e sensoriamento remoto para além da caracterização areal/linear da bacia, estão ampliando as análises, criando apontamentos e critérios para utilizá-los no planejamento do terreno (priorização de bacias/ adequação local de bacias, hidrodinâmica de bacias e relação hidrológica e relevo e uso dos parâmetros para criação de indicadores de uso) com o propósito de minimizar impactos mais atuantes na dinâmica hídrica, com o destaque para bacias urbanas.

Embora o Brasil tenha avançado na gestão de impactos ambientais urbanos por meio da gestão integrada implementada por alguns órgãos públicos, observa-se ainda estudos desconexos e desprovidos de metodologias integralizadoras das políticas públicas. As cidades médias brasileiras detêm atualmente relevante papel no que tange ao seu contingente populacional e de sua força polarizadora com relação às cidades menores de seu entorno.

A cidade de Eunápolis se destaca como importante centro urbano no Estado da Bahia com quantitativo populacional de 114. 396 habitantes (BRASIL, 2021a). A microbacia do Córrego Grande (MBCG), localizada em Eunápolis, já apresenta problemas na qualidade da água e impactos no terreno; assim, o diagnóstico dos fatores desencadeadores destes impactos torna-se essencial, uma vez que, oferece dados para operacionalização dos planos de gestão urbana, com intuito de minimizar os danos à saúde e ao ambiente, já em curso.

Neste contexto, este artigo tem o objetivo de realizar análise morfométrica como subsídio à identificação de impactos ambientais na Microbacia Hidrográfica do Rio Córrego Grande, Eunápolis (BA). A partir de uma abordagem sistêmica, os instrumentos metodológicos utilizados foram técnicas de geoprocessamento e sensoriamento remoto para estudo avançado da morfometria, confecção dos perfis longitudinal e transversal do rio, mapas de uso solo e de APPs (Área de Preservação Permanente), entre outros índices de análise terreno.

\section{LOCALIZAÇÃO E CARACTERIZAÇÃO DA ÁREA DE ESTUDO}

A Microbacia Hidrográfica do Rio Córrego Grande (MBCG) está localizada no município de Eunápolis sob as coordenadas geográficas de $16^{\circ} 22^{\prime} 39^{\prime \prime} L$ at $\mathrm{S}$ e 39 $37^{\prime} 00^{\prime \prime}$ Long W e $16^{\circ} 21^{\prime} 30^{\prime \prime}$ Lat 39 $34^{\prime} 49^{\prime \prime}$ Long W como pode ser observado no mapa de localização da Figura 01. O referido município pertencente à Mesoregião Sul Bahiana e Microrregião de Porto Seguro (BAHIA, 2020). Detém contingente populacional de 114. 396 habitantes com uma densidade demográfica de 84,97 hab./km² distribuídos na área urbana e rural (BRASIL, 2020).

A MCG limita-se em ângulo paralelo com as bacias do Rio João de Tiba e Santo Antônio. Neste caso em particular a microbacia analisada, constitui-se num sistema de drenagem endorréico cuja foz está conectada à bacia dos Rios João de Tiba/Santo Antônio (Figura 01), nível de base regional.

A Microbacia do Córrego Grande drena em maior parte os terrenos geológicos constituídos por sedimentos areno-argilosos do Grupo Barreiras que 
consolidam as feições geomorfológicas dos Tabuleiros Costeiros, unidades de relevo dominante na área investigada. Ao longo das calhas e do leito do Rio Córrego Grande foram mapeados afloramentos de rochas granítico-gnaisse e granulitos (DANTAS, 1999).

Em maior grau de detalhe as unidades geomorfológicas, constituem-se essencialmente de planícies costeiras produzidas pelo retrabalhamento erosivo dos Tabuleiros Costeiros consolidados no Grupo Barreiras. O vale do Rio Córrego Grande é circundado por vertentes com declividades de 10 a $25 \stackrel{\circ}{\circ}$. Grande parte da bacia drena os tabuleiros com exceção das porções sudeste e nordeste que ocorrem sobre superfícies aplainadas degradadas (BASTOS; MEDIDA; DANTAS; SHINZATO, 1999).

Figura 1. Localização geográfica da Microbacia do Rio Córrego Grande - Eunápolis (MCG) e Modelo Digital de Elevação de Terreno (MDET) e bacias hidrográficas adjacentes.

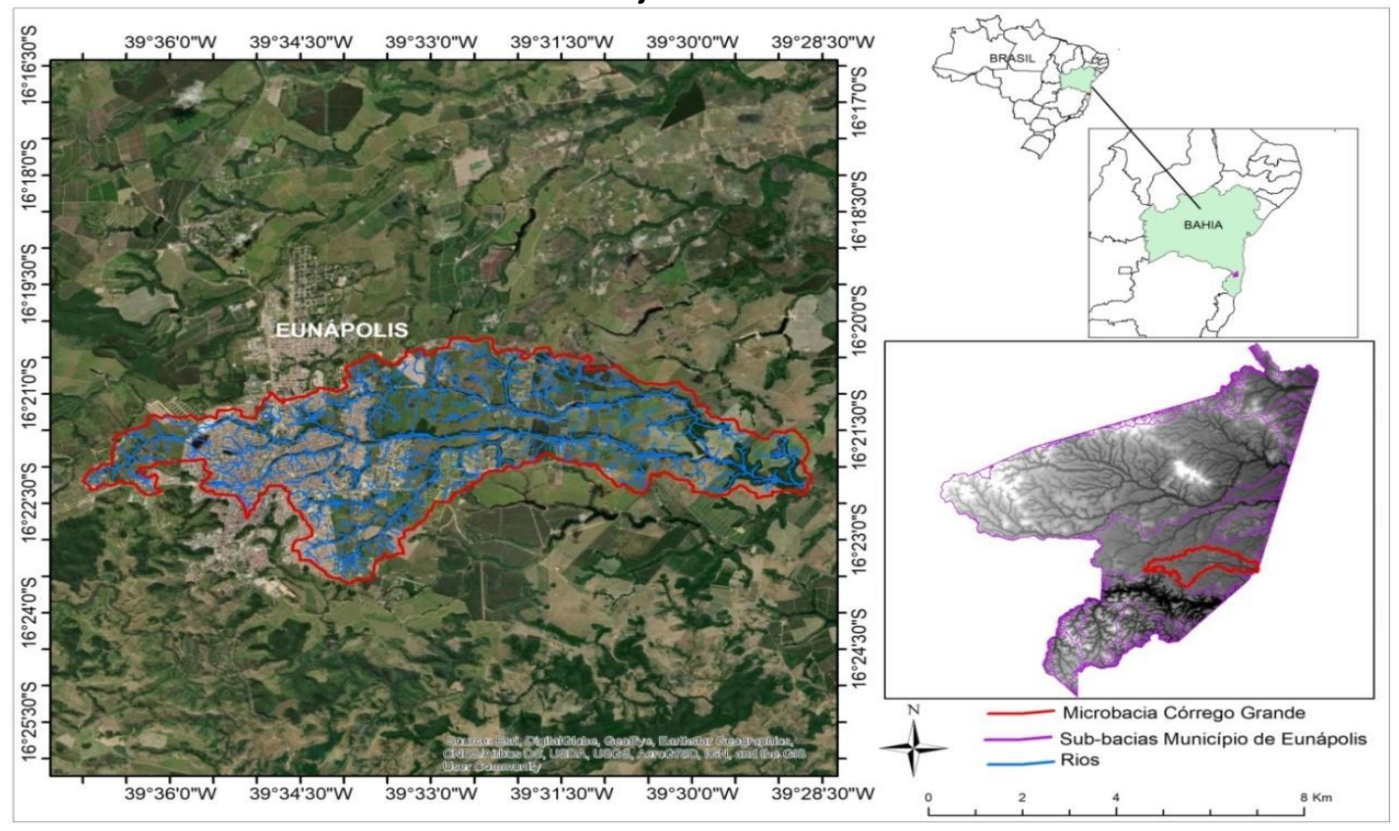

Fonte: Elaborado pelos autores, 2021

Os Tabuleiros Costeiros no município de Eunápolis subdividem-se em tabuleiros pouco, médio e muito dissecado e na área da bacia analisada predominam os tabuleiros com moderado a alto grau de intemperismo químico e porosidade primária alta (DANTAS; MEDIDA; SHINZATO, 2002).

Com relação aos seus aspectos climáticos na Região Extremo Sul da Bahia o período chuvoso é representado pelos meses de novembro a janeiro com máximo climatológico em dezembro (RAO e HADA, 1990). As precipitações no período indicado estão associadas às penetrações da $\mathrm{mPa}$ (Massa Polar Atlântica). A variabilidade das precipitações também sofre forte influência do posicionamento da ZACAS (Zona de Convergência do Atlântico Sul e dos VCANs (Vórtices Ciclônicos de Altos Níveis), e das anomalias da TSM (Temperaturas na Superfície no Mar) e pela variabilidade da alta subtropical do Atlântico Sul, como pode ser observado em Chaves e Nobre (2004). Localmente a BHE detém em toda a sua extensão o tipo climático Aw, enquadrando-se na classe Clima Tropical, quente e úmido em conformidade com a proposta por Köeppen (1936). 
Quanto às temperaturas, observam-se valores superiores à $18^{\circ} \mathrm{C}$ e índice pluviométrico anual de $990 \mathrm{~mm}$ e média mensal de mensal de $60 \mathrm{~mm}$, (CPRM, 1999). As coberturas vegetacionais de Floresta Ombrófila Densa e Floresta Atlântica com Vegetação Secundária e Atividades Agrícolas.

As classes de solos predominantes são os Argissolos Vermelho-Amarelo distrófico com textura arenosa/média e média/argilosa com ou sem presença de fragipan e Latossolos Amarelos distróficos caracterizados como solos profundos, de coloração amarelada com perfis muito homogêneos, com boa drenagem e baixa fertilidade natural em sua maioria (BRASIL, 2006d).

\section{PROCEDIMENTOS METODOLÓGICOS}

Os procedimentos metodológicos adotados para atingir o objetivo proposto foram fundamentados pela abordagem sistêmica e integrou análises hidrológicas (quantitativa) e o uso do solo da microbacia hidrográfica do Rio Córrego Grande. Para atingir o objetivo proposto foram realizados levantamento bibliográfico e cartográfico (no site da Superintendência de Estudos Econômicos e Sociais da Bahia - SEI e do Instituto Brasileiro de Geografia e Estatística - IBGE) sobre o município de Eunápolis.

A operacionalização dos dados (manipulação e processamento), análises e elaboração dos mapas em escala 1:60.000 foram realizados com o emprego do programa ArcGis 10.3 e seus módulos (Analysis Tools, Spatial Analyst Tools, Spatial Statistics Tools).

O mapa de declividade foi gerado a partir da ferramenta Slope do ArgGis em 5 classes em graus (Empresa Brasileira de Pesquisa Agropecuária - EMBRAPA). 0 mapa de entalhamento dos vales foi gerado através do uso da ferramenta Spatial Analist Tools/Hidrology de acordo com o método preconizado por Guimarães et. al (2017).

A microbacia do Rio Córrego Grande e sua hidrografia foram delimitadas por meio do Modelo Digital de Elevação gerado pela imagem ALOS PALSAR-FBS, e utilizou o procedimento indicado por Marques (2017). Foram gerados rios com limiar de 500 metros para privilegiar a inclusão de pequenos canais, importantes para a análise morfométrica.

Como referência para confecção dos perfis longitudinais e transversais do rio principal foi utilizado o MDE e a ferramenta de Interpolation Shape - módulo Spatial Anayst Tools - ArcGis 10.3 com posterior criação do perfil com a ferramenta Profile - 3 D Analyst Tools.

O Indice de Entalhamento vales foi gerado no ArcGis 10.3 através das operacionalidades da ferramenta Spatial Analyst e o Índice de Rugosidade do Terreno (ITR) foi produzido a partir do programa SAGA GIS conforme método de Riley; De Gloria; Elliot (1999).

A Textura Topográfica do relevo foi realizada segundo a classificação de França (1968), seguindo os termos quantitativos em função dos valores da densidade de drenagem de Freitas (1952).

Para a pesquisa foi efetuada a análise comparativa entre Modelo Digital de Terreno e os mapas hidrográficos produzidos pelo Serviço de Informações dos Municípios Baianos (BAHIA, 2003) na escala 1:100.000.

Posteriormente, foram calculados com o ArcGIS, os parâmetros morfométricos seguindo as proposições de Horton (1945), Strahler (1952), Schumm 
(1963) Vilela e Matos (1975), Christofoletti (1980) e Tonello (2006). Estes parâmetros refletem as características geométricas, de relevo, drenagem, e o comportamento hidrológico da bacia em estudo; as fórmulas e métodos estão condensado no Quadro 1.

Quadro 1. Parâmetros morfométricos de uma microbacia hidrográfica do Rio Córrego Grande espessura, textura topográfica gradientes de canais

\begin{tabular}{|c|c|c|}
\hline $\begin{array}{l}\text { Características } \\
\text { morfométricas }\end{array}$ & Parâmetros & Descrição \\
\hline \multirow{6}{*}{ Geometria } & Área (A) & $\begin{array}{l}\text { Compreende os divisores topográficos e seu plano interior, } \\
\text { projetado na horizontal (TONELLO, 2006). }\end{array}$ \\
\hline & Perímetro (P) & $\begin{array}{l}\text { Comprimento da linha do divisor de águas (TONELLO, } \\
\text { 2006). }\end{array}$ \\
\hline & $\begin{array}{l}\text { Coeficiente de Compacidade } \\
\text { (Kc) }\end{array}$ & 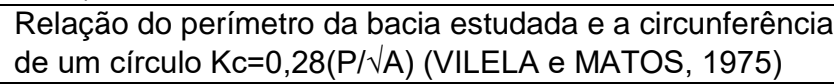 \\
\hline & Índice de Circularidade (Ic) & $\begin{array}{l}\text { Proporção da área, com relação entre a área da bacia e o } \\
\text { perímetro ao quadrado } I C=\left(12,57^{a}\right) \mathrm{P}^{2}(\mathrm{STRAHLER}, 1957)\end{array}$ \\
\hline & Fator de Forma (Kf) & $\begin{array}{l}\text { Relação da forma da bacia e o comprimento do eixo } \mathrm{Kf}= \\
\mathrm{A} / \mathrm{L}^{2} \text { (VILELA e MATOS, 1975). }\end{array}$ \\
\hline & Densidade hidrográfica (Dh) & $\begin{array}{l}\text { Compara a frequência de cursos de água e estima a } \\
\text { capacidade de gerar novos cursos d'água. } \mathrm{Dh}=\mathrm{N}^{0} \text { canais/ A }\end{array}$ \\
\hline \multirow{9}{*}{$\begin{array}{l}\text { Rede de } \\
\text { drenagem }\end{array}$} & Número total de canais & Quantidade de afluentes da bacia hidrográfica. \\
\hline & $\begin{array}{l}\text { Comprimento do curso } \\
\text { principal (L) }\end{array}$ & $\begin{array}{l}\text { Comprimento do canal principal considerando suas } \\
\text { simetrias (SCHUMM, 1963). }\end{array}$ \\
\hline & $\begin{array}{l}\text { Comprimento total dos } \\
\text { cursos d'água (Lt) }\end{array}$ & Soma os comprimentos totais das drenagens da bacia. \\
\hline & Comprimento do Eixo (Le) & $\begin{array}{l}\text { A distância entre a foz do rio principal e a distância mais } \\
\text { longínqua da divisão topográfica. }\end{array}$ \\
\hline & $\begin{array}{l}\text { Densidade de Drenagem } \\
\text { (Dd) }\end{array}$ & $\begin{array}{l}\text { Relação entre o comprimento total dos canais e a área da } \\
\text { bacia } \mathrm{Dd}=\mathrm{Lt} / \mathrm{A} \text { (VILELA e MATOS, 1975). }\end{array}$ \\
\hline & Padrão de Drenagem (Pd) & Análise proposta por Christofoletti (1980) \\
\hline & $\begin{array}{l}\text { Coeficiente de Manutenção } \\
(\mathrm{Cm})\end{array}$ & $\begin{array}{l}\text { Área mínima necessária para a manutenção de um metro } \\
\text { de canal de escoamento, sendo a relação de } 1 \text { e Dd } \\
\text { multiplicado por } 1000 \mathrm{Cm}=(1 / \mathrm{Dd}) 1000 \text { (SCHUMM, 1963). }\end{array}$ \\
\hline & Ordem dos rios & Método proposto por Strahler (1957). \\
\hline & Índice de Sinuosidade (Is) & $\begin{array}{l}\text { Proporção resultante da relação entre o comprimento do } \\
\text { canal com a distância vetorial entre os dois pontos } \\
\text { extremos do canal principal Is }=100(\mathrm{~L}-\mathrm{DV}) \mathrm{L} \text { (SCHUMM, } \\
\text { 1963). }\end{array}$ \\
\hline
\end{tabular}

Fonte: Elaborado pelos autores, 2021

O mapa de uso e cobertura do solo foi obtido no site da Fundação Brasileira para o Desenvolvimento Sustentável (https://geo.fbds.org.br/). O mapeamento foi realizado por meio da classificação supervisionada de imagens RapidEye, ano base 2013, corrigido para 2021. A conferência e edição vetorial foi realizada na escala de 1:10.000. Foram mapeadas 6 classes de uso e cobertura, a saber: formação florestal, formação não florestal, água, área edificada, área antropizada e silvicultura. A delimitação das áreas edificadas respeita os limites estabelecidos pela Base Cartográfica Contínua do IBGE (2013). 


\section{RESULTADOS E DISCUSSÕES}

abaixo:

Os resultados da caracterização morfométrica são apresentados no quadro

Quadro 2. Resultados dos Índices morfométricos para a microbacia do Córrego Grande - Eunápolis- Ba.

\begin{tabular}{|c|c|c|c|}
\hline \multicolumn{2}{|c|}{ Características morfométricas } & Resultados & Unidade \\
\hline \multirow{6}{*}{ Geometria } & Área $(A)$ & 39,39 & $\mathrm{~km}^{2}$ \\
\hline & Perímetro $(\mathrm{P})$ & 48,84 & $\mathrm{~km}$ \\
\hline & Coeficiente de Compacidade (Kc) & 2,17 & m.m2 \\
\hline & Índice de Circularidade (Ic) & 0,20 & - \\
\hline & Fator de Forma (Kf) & 0,18 & - \\
\hline & Densidade hidrográfica (Dh) & 3,60 & Canais \Km2 \\
\hline \multirow{9}{*}{ Rede de drenagem } & Número total de canais & 142 & - \\
\hline & Comprimento do curso principal (L) & 16,62 & $\mathrm{~km}$ \\
\hline & Comprimento total dos cursos d'água (Lt) & 93,26 & $\mathrm{~km}$ \\
\hline & Comprimento do eixo & 14,56 & $\mathrm{~km}$ \\
\hline & Densidade de Drenagem (Dd) & 2,36 & $\mathrm{Km} \cdot \mathrm{km}^{2}$ \\
\hline & Padrão de Drenagem (Pd) & Dendrítica & \\
\hline & Coeficiente de manutenção & 422,3 & $\mathrm{~m} 2$ \\
\hline & Ordem da Bacia (Ob) & 4 & \\
\hline & Índice de Sinuosidade (Is) & 2,09 & $\mathrm{Km} \cdot \mathrm{km}-1$ \\
\hline
\end{tabular}

Fonte: Elaborado pelos autores, 2021

A MBCG localiza-se na porção centro leste do município e abarca quase a totalidade da área urbana. Possui uma área de $39,405 \mathrm{~km}^{2}$ estruturada num padrão de drenagem dendrítico com hierarquização fluvial 4, conforme Strahler (1952). A análise da morfologia da drenagem demonstrou extensa ramificação de canais bem distribuídos entre suas margens direita e esquerda.

Os rios fluem em sua maioria sobre os Tabuleiros Costeiros em coberturas detríticas rasas, em áreas cujos cursos de água atuam como vetor erosivo induzidos, em grande parte, pela dinâmica sazonal de precipitações que provê chuvas frequentes (média acima de $1000 \mathrm{~mm}$ anuais - CONCEIÇÃO (2020) e bem distribuídas ao longo do ano.

Os resultados dos índices morfométricos demonstraram que a microbacia possui baixa susceptibilidade aos transbordamentos/inundações quando consideramos os resultados dos índices de compacidade $(2,17 \mathrm{~km})$, circularidade $(0,20)$ e fator de forma $(0,18)$. A correlação desses três índices indica que a bacia possui forma consideravelmente alongada, o que contribui para o processo de escoamento e para baixa susceptibilidade a enchentes; elemento importante em se tratando de bacia urbana densamente povoada. Essa condição, supostamente restringe impactos erosivos mais severos devido à boa distribuição dos processos de erosão fluvial ao longo da bacia é confirmada também pela alta densidade hidrográfica, padrão de drenagem e forma alongada da bacia.

Embora a susceptibilidade a enchentes seja baixa, os resultados dos parâmetros de densidade de drenagem, densidade hidrográfica, desnível altimétrico, textura topográfica e declividade do terreno esboçam valores indicativos de elevada potencialidade para ocorrência de movimentos de massa.

Para o valor de densidade de drenagem (Dd) foi tomado como referência o valor de $0,5 \mathrm{~km} \cdot \mathrm{km}^{2} \mathrm{em}$ bacias com drenagem pobre a $3,5 \mathrm{~km} \cdot \mathrm{km}^{2}$ ou mais em 
bacias bem drenadas (VILLELA e MATTOS, 1975). O valor encontrado para a MBCG foi de 2,36 km/ $\mathrm{km}^{2}$ e indica uma microbacia de média/alta densidade de drenagem e com boa capacidade de infiltração. Os valores considerados altos podem indicar solos permeáveis o que induz a uma resposta hidrológica rápida aos eventos de chuva, podem estar relacionadas a áreas com vegetação esparsa e com probabilidade de erosão (SUKRISTIYANTI e LESTIANA, 2018).

A acentuada densidade de drenagem promove eficiente esculturação dos vales e é uma boa referência para o desenvolvimento do sistema de drenagem (CHRISTOFOLETTI, 1980). Neste contexto, a MBCG corresponde a uma microbacia bem drenada devido aos altos índices pluviométricos no seu interior consorciado a presença de solos areno-argilosos permeáveis e favoráveis à formação de níveis de nascentes e lagoas nas áreas de topo do tabuleiro. No entanto, a presença de um tecido urbano denso em grande parte da área da bacia impede a fluidez natural da água e já são evidentes processos de erosão em alguns pontos da área urbana bacia.

Além disso, o poder público local não faz um manejo adequado nem da água superficial nem da água subterrânea, uma vez que muitas residências coletam água em poços artesianos sem um planejamento de solo urbano. Esse fato pode ser considerado um risco em longo prazo uma vez que pode acelerar processos erosivos e criar outros impactos tais como contaminação do solo e da água. Dash et al. (2019) aplicaram análise morfométrica para planejar medidas de conservação do solo e da água por meio de técnicas geoespaciais na microbacia Seoni, bacia Hidrográfica Madhya Pradesh localizada na Índia e utilizaram parâmetros similares aos utilizados neste estudo. Os autores constaram importantes elementos passíveis de dirimir questões de planejamento de uso solo/água em áreas urbanas densamente povoadas principalmente em relação a medidas específicas de adequação local em relação ao manejo desses importantes recursos.

Os resultados desse estudo evidenciaram que a sub-bacia possui subsolo permeável com escoamento curto, mas com grande infiltração, fenômeno típico de bacias com forma circular como a de Seoni (Dash et. al., 2019). Constataram também que a sub-bacia possui baixo potencial de escoamento superficial o que impossibilita a coleta superficial da água para irrigação, mas viabiliza a coleta subterrânea. Esse dado é importante para bacias urbanas e periurbanas de médio e grande porte como a MBCG, uma vez que, muitas cidades da hinterlândia do Brasil, pela ausência de estruturas de saneamento, utilizam o recurso sem o devido planejamento geotectônico/hidrológico da coleta de água subterrânea para fins de dessedentação humana/animais. Tal ação, feita sem uma avaliação do contexto geoecológico biofísico pode trazer impactos significativos nos recursos hídricos.

No caso específico da bacia de Seoni, ações de coleta de água subterrânea foram indicadas em detrimento da coleta superficial, predominante. Na MBCG foi possível verificar um processo de escoamento superficial alto, bem distribuído e boa capacidade de infiltração, no entanto, a maior parte das residências possuem poços artesianos e captam água sem uma estratégia de planejamento/orientação do uso. Dessa maneira, os riscos de erosão tendem a aumentar quando somadas a baixa presença de vegetação, a alta exploração dos poços e consequentemente um menor índice de aproveitamento de captação da água superficial.

Métodos morfométricos são eficientes para análise de escoamento, fator chave para desencadeamento de processos erosivos bem como para 0 planejamento de bacias (SUKRISTIYANTI et al. 2018; MURALITHARAN e 
PALANIVEL, 2019). Na MBCG há propensão ao escoamento concentrado. Muralitharan e Palanivel (2019) modelaram o escoamento de sub-bacias drenagem na região de Karur, Tamil Nadu - Índia por meio de Sistemas de Informação Geográfica e Sensoriamento Remoto e do uso de parâmetros morfométricos clássicos.

Os resultados dessa pesquisa apresentam a classificação das sub-bacias em graus de escoamento (baixo, médio e alto) e uma relação entre as variáveis morfométricas como densidade de densidade de drenagem, razão de bifurcação, textura de drenagem e razão de circularidade. A densidade hidrográfica e fator de forma apresentou uma conexão direta com escoamento e, portanto, maior propensão ao escoamento o que representa efeito direto no processo erosivo o que permitiu a caracterização da bacia de forma consistente nos aspectos para identificação e gestão dos de impactos.

Em se tratando de uma área urbana essa condição pode representar risco ambiental. Muitas sub-bacias que se encontram em nível alto ou muito alto de escoamento estão sendo exploradas sem o manejo adequado às condições para o armazenamento de água, fluidez e manutenção do fluxo de água subterrânea, elemento relevante nessa região com alta densidade demográfica, uma vez que pode provocar escassez do recurso a médio e longo prazo e perda da qualidade da água.

Estudos realizados na área da MBCG indicam predominância de terrenos constituídos por sedimentos detríticos de composição diversa - arenitos, siltitos, argilitos e cascalho (CARVALHO; RAMOS, 2010). Essa composição geológica é fortemente influenciada pela textura topográfica grosseira (Valor 2,38). Este fator é facilitador para processos de infiltração e erosão hídrica devido às discordâncias erosivas produzidas pelas descontinuidades litológicas do Grupo Barreiras, fator que reforça a probabilidade de riscos de erosão e movimentos de massa. Esse dado sugere também solos com menor resistência a erosão. Dessa forma há grande infiltração e água, mas também uma grande coleta de água para usos diversos.

A sinuosidade controla a velocidade do escoamento e o enquadramento dos padrões de canais fluviais. Na bacia de estudo o valor de 2,09 indica canais sinuosos com maior controle na velocidade de escoamento. Esse dado revela um importante indicador de impacto ambiental uma vez que baixo fator de escoamento se refere a maior dificuldade de dispersão de poluentes e nesse caso, em uma bacia sem tratamento de resíduos como na MBCG é um agravante.

Esse dado correlacionado com a amplitude topográfica da bacia reforça 0 papel pontual do fator escoamento e erosão, uma vez que o valor foi de 73 metros. Para uma bacia de 14,68 km localizada na planície costeira com rochas friáveis, com alta pluviosidade e temperatura, este dado se torna um importante indicador para identificação de impactos e para o planejamento.

Quanto à vulnerabilidade à erosão, os resultados do índice de rugosidade do terreno (ITR) e do grau de profundidade dos vales mostram probabilidade de avanço erosivo controlado pelos rios, com destaque para o rio principal. O entalhamento dos vales é de médio a alto. Sendo assim, a calha fluvial ultrapassa o setor do médio do curso do rio principal e evolui de forma proeminente rumo ao alto curso, gerando grande quantidade de nascentes face ao elevado entalhamento sobre terrenos constituídos por descontinuidades litológicas. 
O resultado do coeficiente de manutenção revela que microbacia possui área considerada conforme SCHUMM (1963) boa para manutenção dos seus canais fluviais permitindo a perenidade desses cursos d'água.

Os resultados do índice de rugosidade do terreno (ITR) são coerentes quando relacionados aos dados de risco de erosão por declividade, tipo de rocha e contexto de relevo. Expressam valores altos (entre 60 e 88 de ITR - Figura 2) nas áreas do leito rio principal e nos leitos dos principais afluentes. Além disso o ITR permitiu a espacialização de amplas áreas planas referentes aos platôs dos tabuleiros que indicam áreas disponíveis para usos diversos agropecuários e expansão urbana.

Figura 2. Declividade, Índices de Entalhamento vales e Rugosidade do Terreno (ITR) com desenho dos perfis transversal e longitudinal da Microbacia do Córrego Grande

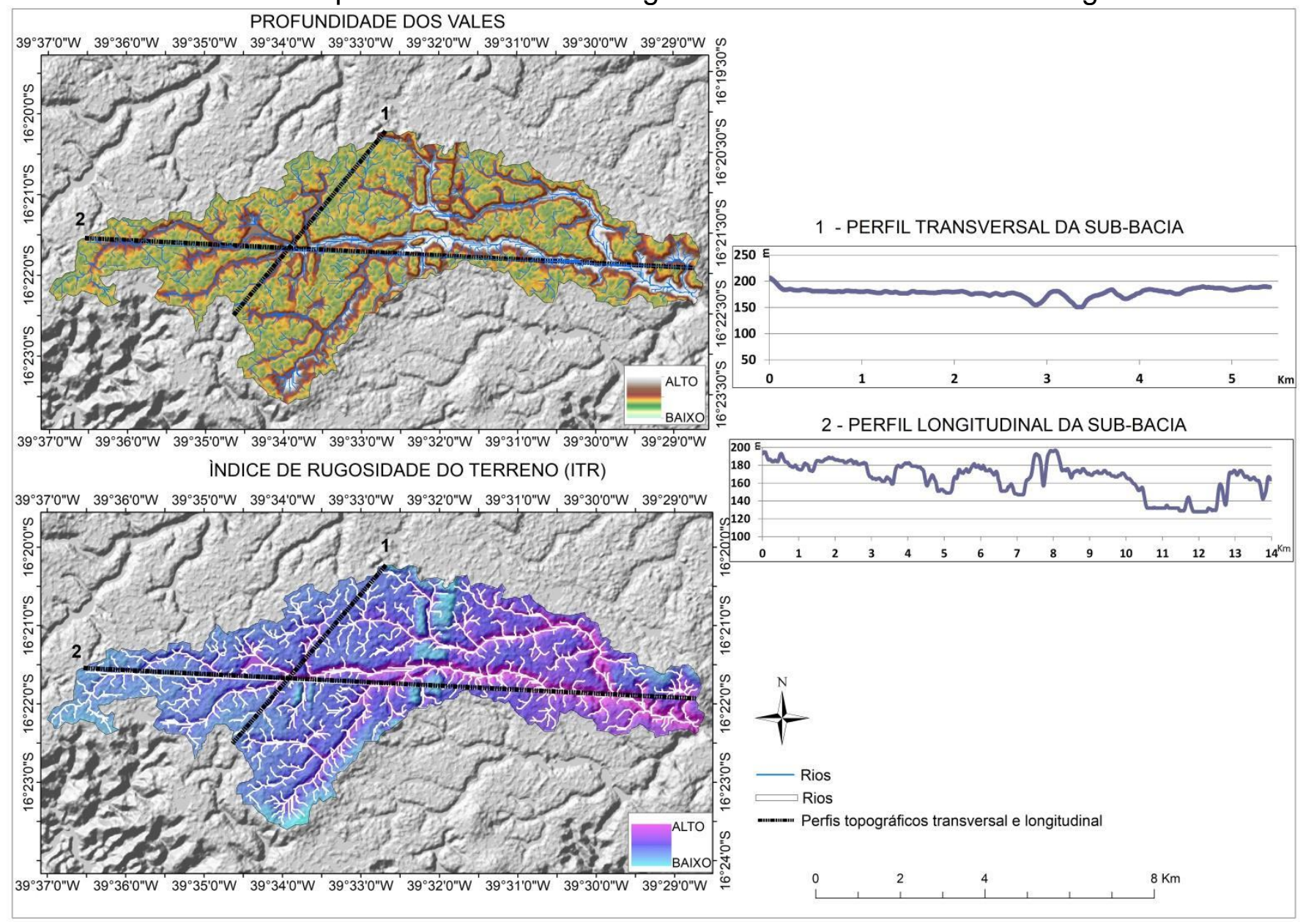

Fonte: Elaborado pelos autores, 2021

Conforme indicado na Figura 02 nas bordas centro-sul e nordeste, significativas porções de áreas da bacia hidrográfica revelam zonas de escoamento fluvial eficiente. Situação ocasionada devido às elevadas declividades e pela proximidade das vertentes de média e baixa dissecação das áreas de topo do tabuleiro. Essas circunstâncias geram em escala de detalhe a manifestação de processos erosivos difusos de baixa magnitude. Porém, cabe ressaltar que em algumas localidades ocorram eventos como rastejos e produção de formas erosivas esculpidas pelo escoamento superficial como ravinas e voçorocas. 
As formas erosivas mencionadas são identificadas nas vertentes em interfacie com o platô do tabuleiro. Uma informação digna de nota é que essas áreas são revestidas por pastagens ao longo dos taludes e extensivamente aproveitadas pela silvicultura de eucalipto sobre as áreas de topo.

Ao analisar o Rio Córrego Grande por meio dos perfis do rio e dos perfis longitudinais e transversais da microbacia, foi possível observar (Figura 3) que seu leito fluvial está em fase de franco entalhamento erosivo dos vales. São identificados degraus erosivos originados pela erosão decorrente da superimposição da drenagem no relevo marcada pela diferença altimétrica em relação ao nível de base local. Conclusões resultantes do cálculo da diferença altimétrica que foi 73 metros, os fatores de textura terreno, densidade de drenagem e densidade hidrográfica podem indicar irregularidades perfil e assim o poder erosivo em curso no rio.

Figura 3. Hierarquia Fluvial com destaque para o perfil topográfico do Rio Córrego Grande
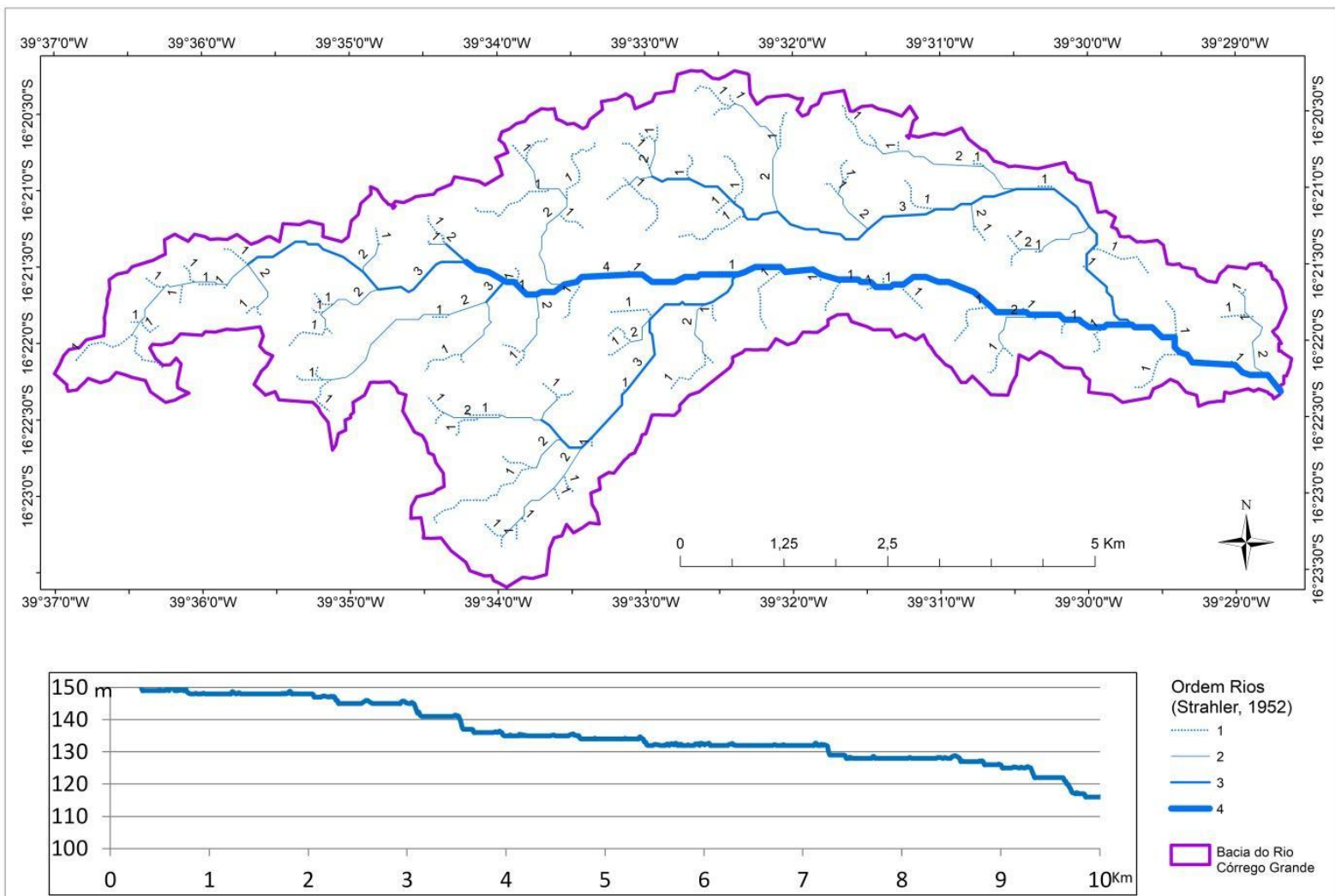

Fonte: Elaborado pelos autores, 2021

Os processos morfodinâmicos reinantes na área da bacia hidrográfica possuem íntima relação com os parâmetros de reajustamento erosivo nos canais fluviais, com a erodibilidade, com as declividades acentuadas das vertentes, intensidade das precipitações e os efeitos danosos da urbanização mal planejada. Esses fatores têm produzido sobre a bacia perdas de solos das zonas de topo e vertentes impondo ao Rio Córrego Grande assoreamento de seu leito.

Banerjee et al. (2015) ao avaliarem a morfometria da bacia hidrográfica de Swarnrekha, Índia por meio de SIG destacaram a importância dessa quantificação morfométrica para a priorização de bacias como um indicador de planejamento e gestão de uso solo e da água. Dessa maneira, indicadores seriam melhor 
trabalhados para dirimir questões do planejamento socioambiental dos recursos hídricos e do uso do solo.

Os autores também apresentaram uma correlação direta entre 0 comportamento hidrológico e as formas de relevo associadas o que define um indicador para a gestão das águas. O estudo, ao utilizar os parâmetros morfométricos clássicos destacaram a relação entre as variáveis e assim foi possível estabelecer o potencial para gerenciamento de águas, uma vez que possibilitou a categorização da bacia nos seus aspectos fisiográficos permitindo melhor caracterização dos impactos e dinâmica da bacia.

Priorizar bacias ao mesmo tempo reduz impactos ambientais, permite a otimização de usos sustentáveis como a coleta (reaproveitamento) de água de chuva. No caso específico da bacia hidrográfica de Swarnrekha, Índia, foi possível definir o melhor método para coleta de água definindo o superficial em detrimento ao subterrâneo.

No caso da MBCG quase a totalidade da água flui e dispersa ao mesmo tempo em que a água infiltrada é demandada por milhares de habitantes com vários tipos de coleta via poços, nos rios e lagoas.

Quando associamos os resultados morfométricos com o uso do solo atual na MBCG (Figura 4) observamos o avanço da área urbana sobre a área já degradada, a de solo exposto e o aumento dos cultivos dos grandes sistemas de silvicultura nas áreas rurais e nas áreas periurbanas, além de outros cultivos de produção em escala.

O processo de substituição do solo por usos agropecuários e diversos outros cultivos (silvicultura, mamão) causou diversos impactos no solo e nos recursos hídricos notadamente no que diz respeito aos processos de canalização de rios e ocupação irregular de nascentes e leitos dos rios. Muitas nascentes foram destruídas e/ou aterradas.

Figura 4 Uso e cobertura do solo de 2013 da microbacia do Rio Córrego Grande Eunápolis - Ba

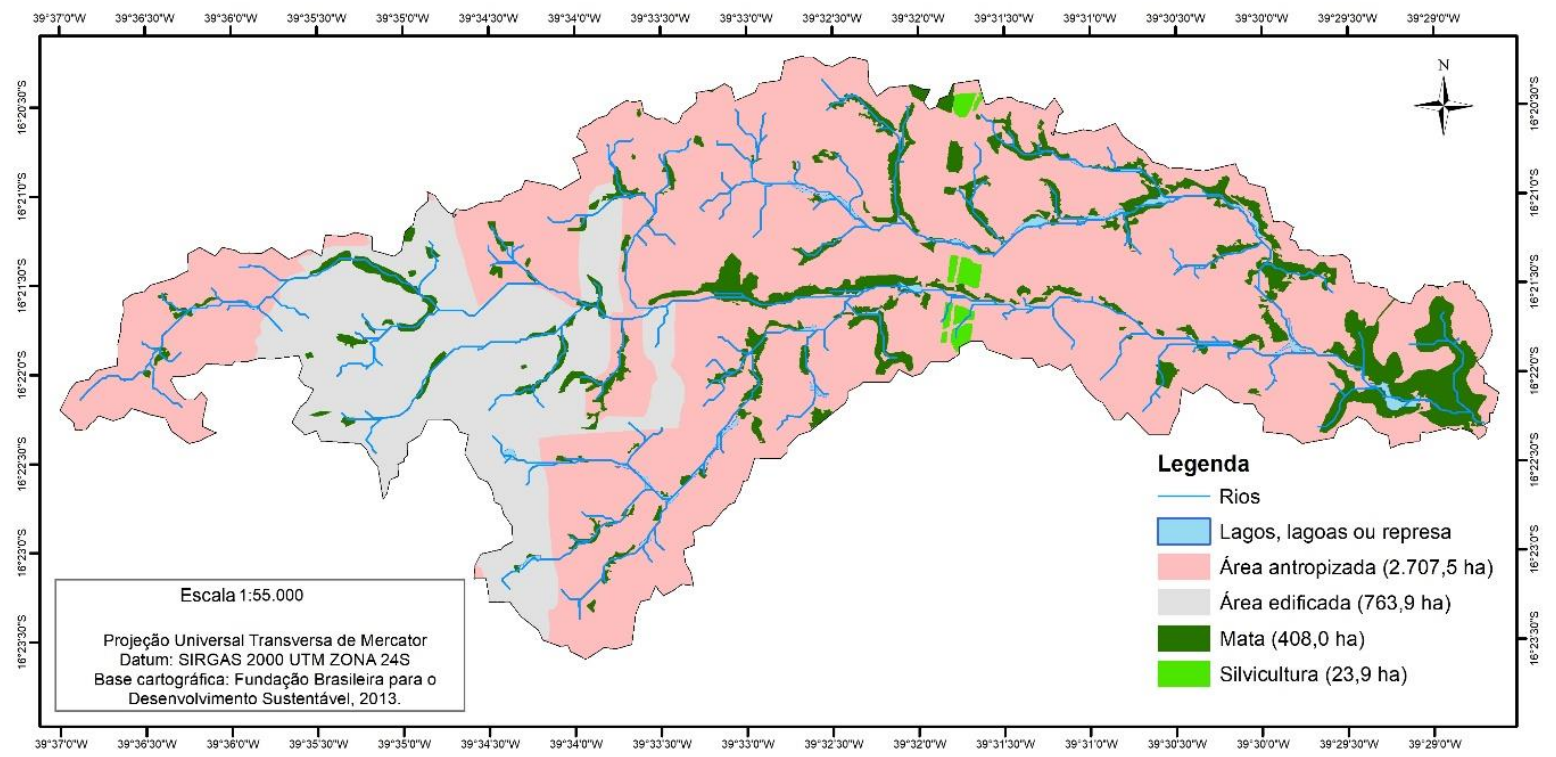

Fonte: Elaborado pelos autores, 2021 
A vegetação presente no município está restrita a fragmentos de mata secundária e capoeira suprimidas em poucas manchas de rios/riachos, dispostas irregularmente e sem mecanismo de proteção biogeográfica. Além disso, muitos desses riachos foram aterrados para compor ruas e são mal drenados, o que altera a dinâmica dos fluxos de água.

A área urbana avança sobre as áreas já degradadas e em diversas áreas das margens dos rios se convertendo no principal indicador de impacto ambiental (Figura 5). Os resultados da pesquisa de campo corroboram estudo feito por Cordeiro (2011) que identificou 15 áreas de risco potencial ligadas aos aspectos geomorfológicos localizados a Noroeste, Sudeste, Sul e Sudoeste de Eunápolis. Essas áreas coincidem com os limites das bordas dos tabuleiros de média a grande dissecação, predominando nessas áreas: probabilidade de deslizamentos, escorregamentos, fluxos de lama e nas partes planas e pouco dissecadas: rastejamento e outros processos como ravinamento e voçorocas.

Figura 5. Uso e cobertura do solo de 2021 da microbacia do Rio Córrego Grande Grande - Eunápolis - Ba

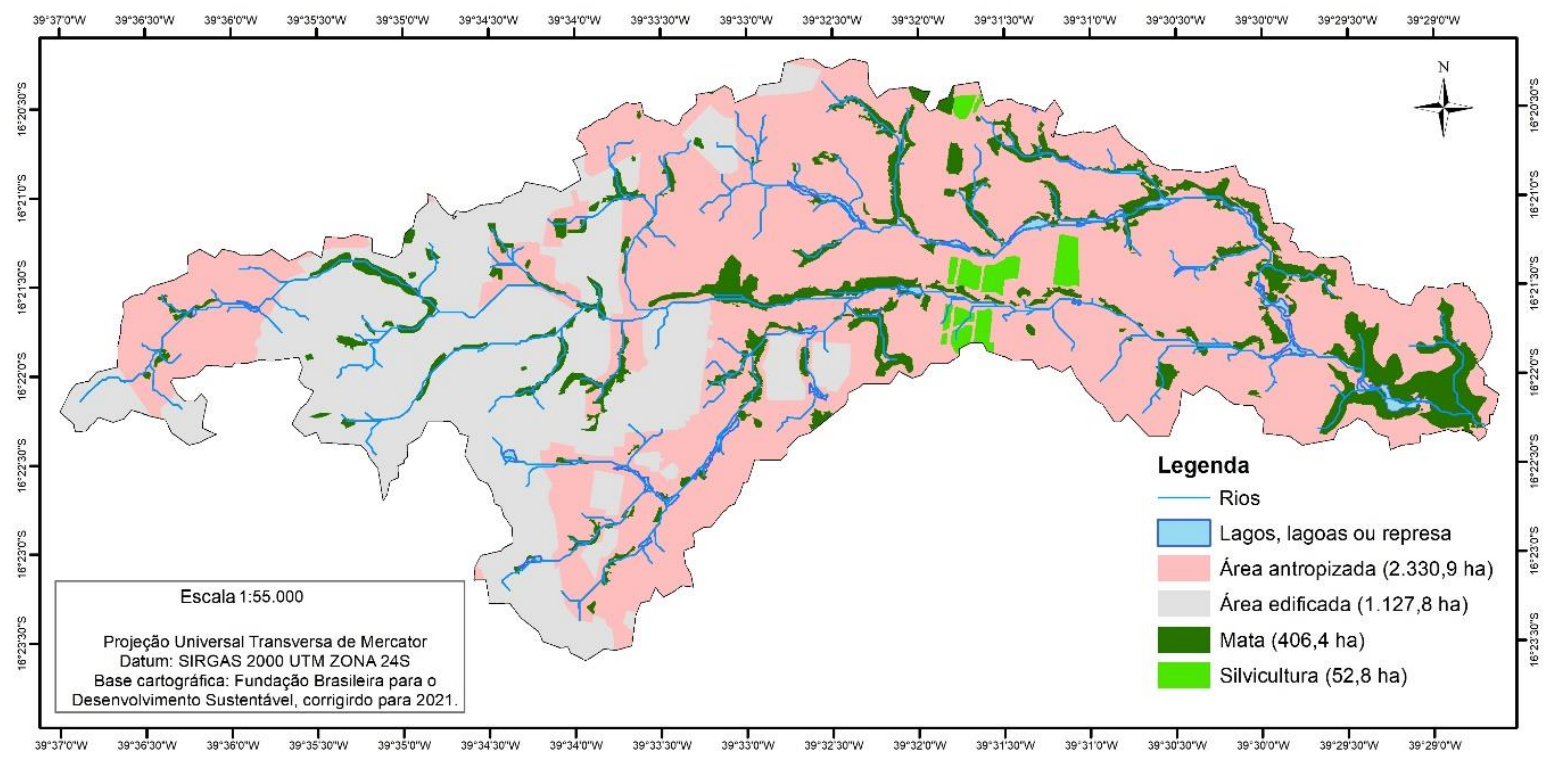

Fonte: Elaborado pelos autores, 2021

A urbanização avança também sobre as APPs (Áreas de Preservação Permanente) e restam poucas áreas florestadas (Figura 06), embora todos os fragmentos de mata urbana se enquadrem em critérios de APPs, tais como bordas de rios, declividade acima de 45을 nascentes e, portanto, objeto de proteção pela Lei 12.651/2012 que determina proteção dessas áreas, sem restrição.

$\mathrm{Na}$ análise do mapa podemos destacar que muitas áreas não possuem mata e ainda que a Lei Maior da proteção e conservação das APPs seja de 2012 sua implementação tem sido negligenciada por municípios/áreas urbanas fator que impacta diretamente a qualidade de vida e a proteção dos recursos hídricos da cidade. 
Figura 6. Uso e cobertura do solo de 2021 das Áreas de Proteção Permanente da bacia da microbacia do Rio Córrego Grande- Eunápolis- Ba

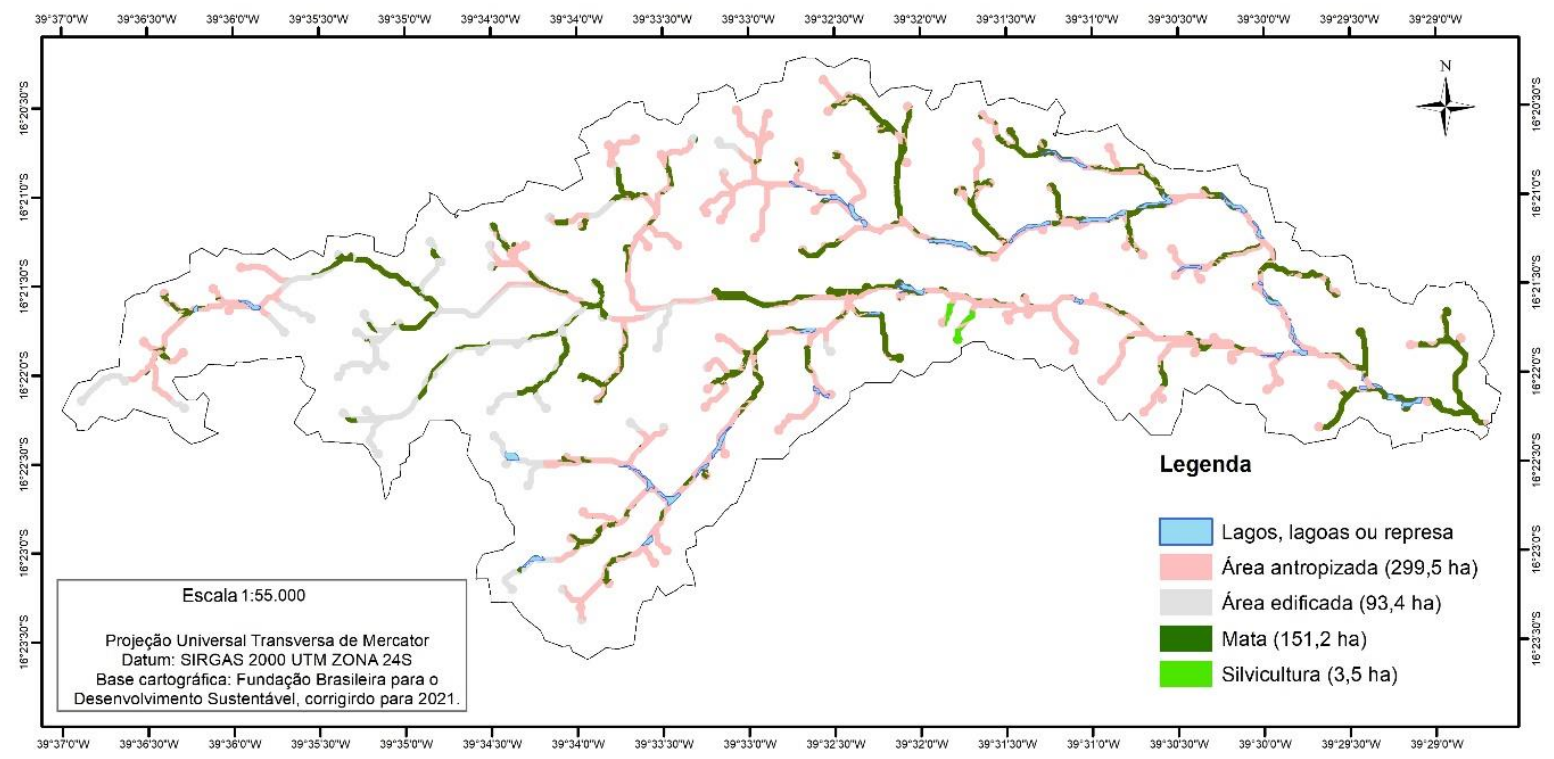

Fonte: Elaborado pelos autores, 2021

Cunha (2010) ao analisar morfologia dos canais urbanos nos trópicos úmidos, no Brasil obteve importantes resultados que explicam muito da realidade das cidades brasileiras como a MBCG. Segundo a autora, a degradação dos leitos das seções transversais reduz a capacidade de fluidez dos canais; o percentual de área urbana na bacia hidrográfica influencia o volume de escoamento superficial e a redução de número e comprimento dos canais por obras de desvios, canalizações e/ou extinção dos mesmos altera os valores de densidade de drenagem e densidade hidrográfica.

\section{CONSIDERAÇÕES FINAIS}

A microbacia do Córrego Grande é caracterizada como de $4^{\mathrm{a}}$ ordem de hierarquia fluvial, ramificada, irregular, de padrão dendrítico, formato alongado e baixa probabilidade de ocorrência de enchentes. A microbacia possui boa capacidade de escoamento e predominância de canais sinuosos que podem ser responsáveis pela minimização de erosão severa em períodos anormais de chuvas e controle do escoamento entre os canais fluviais, principalmente os de 1o ordem.

Valores altos de densidade de drenagem, densidade hidrográfica, textura topográfica relacionada aos significativos índices de entalhamento vales e de rugosidade do terreno associam-se a áreas com impactos ambientais. $\mathrm{O}$ alto valor de densidade de drenagem indica bom desenvolvimento sistema de drenagem com média/alta capacidade de infiltração de água e isso se deve a boa percolação água nos solos dos tabuleiros e os altos e frequentes índices de pluviosidade.

Embora haja boa condição de permeabilidade solo, o avanço das áreas edificadas na bacia, que já ultrapassa $40 \%$ da área total tem gerados impactos ambientais. Tais impactos foram identificados como movimentos de massa nas áreas de vertentes dos tabuleiros de grande média/dissecação, evolução de ravinas e voçorocas que ocorrem relacionados ao uso sem planeamento do solo 
urbano/rural, perfuração indevida de poços para coleta de água, poluição da água pela falta de tratamento dos resíduos.

$\mathrm{Na}$ maioria das vezes, os impactos ocorrem em localidades com construção de residências e arruamentos de forma irregular nos taludes e ao longo das encostas dos tabuleiros de média e alta dissecação. O desflorestamento ao longo das margens do Rio Córrego Grande, canalização dos leitos dos rios e nascentes, impermeabilização dos solos e pastagens nos canais de primeira ordem produzem nos ambientes estudados a morfodinâmica acelerada e maximizam impactos.

Esses fatores aliados a uma alta densidade demográfica no interior da bacia hidrográfica podem contribuir para o incremento do escoamento e ainda que a área tenha demonstrado baixa susceptibilidade a cheias e enchentes podem ocasionar alterações na vazão do escoamento fluvial.

A bacia ainda está em processo de expansão linear remontante dos seus canais fluviais, em paralelo a isto a urbanização e agropecuária avança com ocupações irregulares ao longo das vertentes e fundos de vale ocasionando a degradação dos solos e da água. Neste sentido, eleva-se o impacto ambiental também ao longo das Áreas de Proteção Permanentes da bacia. Nesse caso, as áreas possuem reduzidos fragmentos nas áreas de APPs de margens de rios.

Os canais fluviais com destaque para o rio principal no seu médio/baixo curso possuem maior profundidade do talvegue indicando expressivos desníveis altimétricos, fatos expressos do ITR, declividade e no mapa de entalhamento dos canais. O processo erosivo pode intensificar os riscos de fluxos de lama e deslizamentos até então nas áreas pouco densas da bacia, mas o setor centro/leste e sul apresentam algumas áreas com maior risco. O ITR também demonstra grandes áreas planas aptas à expansão urbana e usos agropecuários.

Ao observar-se grande número de nascentes na porção oeste da MCG oriundas do forte processo de erosão remontante é possível inferir o input de energia controlado pelo rio Córrego Grande e afluentes e este contexto associado ao uso dos solos com baixo percentual de vegetação e predominância de áreas edificadas e sistemas agropecuários elevam 0 risco de ocorrências de processos morfodinâmicos.

Os resultados obtidos nesta pesquisa permitem observar o baixo nível de infraestrutura de saneamento ao longo da bacia. Essas condições associadas às suas características morfométricas e de declividades produzem os efeitos necessários para elevação dos impactos, principalmente ao se considerar a coleta subterrânea de água por uma grande parcela de população, a existência de fossas o que a longo prazo pode comprometer o recurso e a condição de vida de muitos citadinos.

Esse impacto foi bem demonstrado pelo alto valor de sinuosidade que também pode indicar baixo potencial de dispersão dos poluentes.

Considerando essas questões, é de extrema relevância a implantação de políticas públicas que possam considerar adequação/priorização local bacia e assim adequar às políticas de gestão urbana promovidas pelo poder público municipal para conservação e recuperação das suas áreas degradadas pelos efeitos da urbanização e da agropecuária e para a gestão adequada dos resíduos.

Esta pesquisa pode atuar como elemento norteador para implementação de ações e projetos para sustentabilidade ambiental na Bacia Hidrográfica do Córrego Grande visando melhoria da qualidade de vida das comunidades que lá residem, em que pese a necessidade de ampliação do estudo para as bacias de entorno para 
efeito de comparação, fator muito útil para dirimir impactos ambientais indiretos e compreender a dinâmica hídrica na perspectiva regional.

Há de se considerar também a necessidade de mapeamento dos poços e fossas e um estudo hidrogeológico para reunir informações precisas e quantificadas sobre o uso da água superficial e subterrânea e definir melhor os impactos e formas de uso do terreno.

O uso de radar de alta resolução (sensoriamento remoto), associado à aplicação de parâmetros morfométricos areais e lineares clássicos e a inter-relação com outros índices e mapas temáticos por meio do Sistema de Informação Geográfica demonstrou ser eficaz para identificar os impactos erosivos e caracterizar a microbacia.

\section{REFERÊNCIAS BIBLIOGRÁFICAS}

ARAÚJO, Maria Luiza Malucelli. Sustentabilidade das cidades: aspectos conceituais. Raega- O Espaço Geográfico em Análise, v. 12, 2006.

BRASIL. Ministério das Minas e Energia. Projeto RADAMBRASIL: folha SC.24/25 Aracaju/Recife: geologia, geomorfologia, pedologia, vegetação, uso potencial da terra. Rio de Janeiro, 1981.

BAHIA. Governo do Estado. Secretaria de Planejamento. Geinformação: Governo do Estado da Bahia, 2021. Disponível em https://www.sei.ba.gov.br/index.php?option=com_content\&view=article\&id=2599\&/te mid=659.Acesso em 22 de fevereiro de 2021.

BAHIA. Superintendência de Estudos ECONÔMICOS E SOCIAIS DA BAHIA SEI. Mapas digitalizados do Estado da Bahia: base de dados. Salvador: SEI, 2008. CD-ROM.

BANERJEE, Abhishek; SINGH, Prafull; PRATAP, Kamleshwar. Morphometric evaluation of Swarnrekha watershed, Madhya Pradesh, India: an integrated GISbased approach. Applied Water Science, v. 7, n. 4, p. 1807-1815, 2017.

BRASIL. Fundação Instituto Brasileiro de Geografia e Estatística (IBGE). Cidades, 2020. Disponível em https://cidades.ibge.gov.br/. Acesso 2m 19 de jan. 2020a.

BRASIL. Centro Nacional de Monitoramento e Alertas de Desastres naturais (CEMADEN). Disponível em http://www.cemaden.gov.br/municipios-monitorados-2/. Acesso em 13 jan. $2021 \mathrm{~b}$.

BRASIL. Serviço Geológico do Brasil (CPRM). Prevenção de desastres. Disponível em http://www.cprm.gov.br/publique/Gestao-Territorial/Prevencao-de-Desastres/. Acesso em 22 de jan. 2021c.

BRASIL. Empresa Brasileira de Pesquisa Agropecuária (EMBRAPA). Sistema brasileiro de classificação de solos. $2^{\underline{a}}$ ed. - Rio de Janeiro: EMBRAPA-SPI, 2006d. 
BRITANNICA, Encyclopaedia et al. Koppen climate classification climatology. Consultado em 4 de agosto de 2020.

BASTOS, G. M. L. L; de Menezes; MEDINA, G. A. I; DANTAS, G. M. E; SHINZATO, E. A. E. Projeto Porto Seguro-Santa Cruz Cabrália. Diagnóstico Geoambiental, 7. 1999.

CARVALHO, Luiz Moacyr de; RAMOS, Maria Angélica Barreto. Geodiversidade do estado da Bahia. 2010.

CHAVES, R.R.; NOBRE, P. Interactions between the sea surface temperature over the South Atlantic Ocean and the South Atlantic Convergence Zone. Geophysical Research Letters, 31, L03204, 2004.

CHRISTOFOLETTI, A. Geomorfologia. 2ª ed. São Paulo: Edgar Blücher Ltda, 1980.

COELHO NETTO. A.L. A interface florestal-urbana e os desastres naturais relacionados à água no maciço da tijuca: desafios ao planejamento urbano numa perspectiva socioambiental. Revista do Departamento de Geografia. 2005;16:46-60.

COELHO NETTO A.L; AVELAR A.D. O uso da terra e a dinâmica hidrológica. Vulnerabilidade Ambiental. Brasília: MMA.60-73. 2007.

CONCEIÇÃO, Valdir Silva et al. Território de Identidade Costa do Descobrimento. Revista Mbote, v. 1, n. 2, p. 074-099, 2020.

CORDEIRO, C.M. Riscos ambientais geomorfológicos no município de Eunápolis - Ba - mapeamento, avaliação e proposições. In: XIV Simpósio Brasileiro de Geografia Física Aplicada. 2011, Dourados - MS. Anais. Dourados MS.

CUNHA, S. B. Morfologia dos canais urbanos nos trópicos úmidos: a experiência no Brasil. VI Seminário Latino-Americano de Geografia Física II Seminário IberoAmericano de Geografia Física Universidade de Coimbra, 2010.

DA CUNHA, Elias Rodrigues et al. Morphometric characterization of a watershed through SRTM Data and geoprocessing technique. Journal of Geographic Information System, v. 8, n. 02, p. 238, 2016.

DA VEIGA BELTRAME, A. Diagnóstico do meio físico de bacias hidrográficas: modelo e aplicação. Universidade Federal de Santa Catarina, 1994.

DANTAS, Marcelo Eduardo; MEDINA, Antônio Ivo de Menezes; SHINZATO, Edgar. Geomorfologia da Costa do Descobrimento-Extremo Sul da Bahia: municípios de Porto Seguro e Santa Cruz Cabrália. 2002. 
DE ALMEIDA OLIVEIRA, Edson Luis; DE SOUZA ROBAINA, Luis Eduardo. Gerenciamento de áreas de risco em cidades brasileiras: projetos e programas. Ciência e Natura, v. 37, n. 3, p. 366-384, 2015.

DASH, Benukantha et al. Morphometric analysis for planning soil and water conservation measures using geospatial technique. Int. J. Curr. Microbiol. App. Sci, v. 8, n. 1, p. 2719-2728, 2019.

DAS, Sumit. Hydro-geomorphic characteristics of the Indian (Peninsular) catchments: Based on morphometric correlation with hydro-sedimentary data. Advances in Space Research, v. 67, n. 8, p. 2382-2397, 2021.

DE ALMEIDA OLIVEIRA, Edson Luis; DE SOUZA ROBAINA, Luis Eduardo. Gerenciamento de áreas de risco em cidades brasileiras: projetos $\mathrm{e}$ programas. Ciência e Natura, v. 37, n. 3, p. 366-384, 2015.

FRANÇA, G.V. de. Interpretação fotográfica de bacias e de redes de drenagem aplicada a solos da região de Piracicaba. Piracicaba, 1968. 151p. Tese (Doutorado) - Escola Superior de Agricultura "Luiz de Queiroz", Universidade de São Paulo, 1968.

Fundação Brasileira para o Desenvolvimento Sustentável. Mapeamento em Alta Resolução dos Biomas Brasileiros. Disponível em: http://geo.fbds.org.br/. Acesso em: 20 de abril de 2021

JUNIOR, Spatti; PAULO, Eder. Avaliação e comparação das taxas de erosão química e mecânica entre arenitos e argilitos: implicações na evolução geomorfológica da bacia do Rio Corumbataí (SP). 2015.

KOEPPEN, W. Climatic regions of India-Stamp's, Koeppen's. PMF IAS, 1936.

MARGUTI, Bárbara Oliveira et al. Contribuições à nova agenda urbana: 0 relatório do concidades para a Conferência Habitat III. 2018.

MERGEN, Jaqueline; ZANETTI, Valeria Regina; RESCHILIAN, Paulo Romano. Estatuto da Cidade e Cidadania: reflexões sobre a participação popular e gestão democrática na revisão do plano diretor de desenvolvimento integrado de São José dos Campos/SP (2016). Revista Univap, v. 24, n. 46, p. 129-143, 2018.

MOREIRA, L; RODRIGUES, V.A. Análise morfométrica da microbacia da Fazenda Edgárdia - Botucatu (SP). .Eletr.Eng.Florestal. Garça, v.16, n.01, p.9-21, 2010.

MURALITHARAN, J.; PALANIVEL, K. Sub-watershed wise Runoff Modeling using Drainage Morphometric Analysis in Karur District, Tamil Nadu, India through Remote Sensing and GIS Techniques. J. Remote Sens. GIS, v. 10, p. 52-65, 2019.

OLIVEIRA, Celso Maran de; LOPES, Dulce; SOUSA, Isabel Cristina Nunes de. Direito à participação nas políticas urbanísticas: avanços após 15 anos de estatuto da cidade. URBE. Revista Brasileira de Gestão Urbana, v. 10, n. 2, p. 322-334, 2018. 
RAO, V. B.; HADA, K. Characteristics of rainfall over Brazil: annual variations and connections with the Southern oscillation. Theoretical and Applied Climatology, 42, 81- 91, 1990.

OLSZEVSKI, Nelci et al. Morfologia e aspectos hidrológicos da bacia hidrográfica do rio Preto, divisa dos estados do Rio de Janeiro e de Minas Gerais. Revista Árvore, v. 35, n. 3, p. 485-492, 2011.

RILEY, S.J; DE GLORIA, S.D; ELLIOT, R. (1999): A Terrain Ruggedness that Quantifies Topographic Heterogeneity. Intermountain Journal of Science, Vol.5, no. 1-4, pp.23-27. online.

SCHUMM, S. A. Sinuosity of alluvial rivers on the great plains. Geological Society of America Bulletin, v.74, n.9, p. 1089-1100, 1963.

STRAHLER, Arthur N. Hypsometric (area-altitude) analysis of erosional topography. Geol. Soc. America Bulletin (1952), 63, pp. 1117-1142.

STRAHLER, Arthur N. Quantitative analysis of watershed geomorphology. Eos, Transactions American Geophysical Union, v. 38, n. 6, p. 913-920, 1957.

SUKRISTIYANTI, S.; MARIA, R.; LESTIANA, H. Watershed-based morphometric analysis: a review. In: IOP conference series: earth and environmental science. IOP Publishing, 2018. p. 012028.

TONELLO, K. C.; DIAS, H. C. T.; SOUZA, A. L. RIBEIRO, C. A. A. S.; LEITE, F. P. Morfometria da bacia hidrográfica da Cachoeira das Pombas, Guanhães- MG. Revista Árvore, v.30, n.5, pp.849-857, set./out. 2006.

VILLELA, S.M.; MATTOS, A. Hidrologia aplicada. São Paulo: Mcgraw Hill, 1975. 250p. 